\title{
A FORMAÇÃO DO PROFESSOR E AS TECNOLOGIAS DE INFORMÁTICA NA UNIVERSIDADE FEDERAL DE PELOTAS *
}

\author{
Valdinei Marcolla ** \\ Tania Maria Esperon Porto ***
}

\section{Resumo}

Essa pesquisa é fruto das seguintes indagações: Os professores e os alunos dos cursos de Licenciatura consideram relevante a presença de tecnologias de informática no decorrer da formação docente? Como docentes e discentes avaliam os Laboratórios de Informática da Graduação disponibilizados pela universidade? A partir dessas questões investigou-se como alunos e professores dos cursos de Licenciatura da Universidade Federal de Pelotas (UFPel) lidam com a tecnologia informática e/ou digital (computador, interfaces e Internet) no contexto dos Laboratórios de Informática da Graduação (LIGs). Para tanto, a investigou-se os LIGs sediados nos Institutos de Ciências Humanas, Ciências Biológicas e Física e Matemática, utilizando-se para tal um questionário virtual, observações e entrevistas. Assim sendo, os resultados do trabalho apontam dois pontos chaves: a estruturação tecnológica da universidade; e a visão de professores e alunos sobre a inserção das tecnologias de informática no contexto educacional da UFPel.

Palavras-Chave: Ensino Superior, Tecnologia de Informática e Formação de Professores

\section{TEACHER CERTIFICATION PROGRAMS AND THE EDUCATIONAL COMMUNICATIONS AND TECHNOLOGY (ECT) AT FEDERAL UNIVERSITY OF PELOTAS}

Abstract

This paper describes the findings of a research that concerns about the following questions: Do professors and students of Teacher Certification programs of Federal University of Pelotas (UFPel) consider relevant the uses of ECT? How do they assess the computer labs (LIGs) for undergraduate students at UFPel? Considering these questions a research has taken place in order to understand how students and professors of Teacher Certification programs work with ECT in the LIGs. In doing so, LIGs based at Human Sciences Institute, Biology Institute, and Physics and Mathematics Institute had been investigated through a virtual inquiry, observations and interviews. The findings underline two key points: the ECT structure of UFPel; and professors and students' view of ECT employ in the UFPel context.

Key-words: Higher Education; educational communications and technology, Teacher Education

As tecnologias de informática no contexto de formação

A inserção das tecnologias de informática é pensada no contexto de formação de professores? Os professores e os alunos dos cursos de Licenciatura consideram relevante a presença de tecnologias de informática no decorrer da formação docente? Como docentes e discentes avaliam os Laboratórios de Informática da Graduação disponibilizados pela universidade? Entendem esses espaços como de interação e/ou de formação? São essas e outras questões que se procura refletir neste texto, resultado de uma pesquisa realizada no Mestrado em Educação da Faculdade de Educação da Universidade Federal de Pelotas (UFPel).

\footnotetext{
* Relato de pesquisa desenvolvida no curso de Pós-Graduação em Educação - Mestrado em Educação.

** Mestrando em Educação da Universidade Federal de Pelotas (UFPel) - vmarcolla.fae@ ufpel.edu.br - Bolsista Capes.

** Doutora em Educação da Universidade Federal de Pelotas (UFPel), Professora do Programa de Pós-Graduação em Educação -

Mestrado em Educação - taniaporto@terra.com.br.

V. 2 № 1, Março, 2004
} 
Esses questionamentos têm levado-nos a buscar alguns aportes teóricos em Moram (2000) e Kenski (2003, 2001). Assim, Moran (2000) ao pensar as novas tecnologias aplicadas à educação (referindo-se à informática) considera-as importante, pois permitem a ampliação do espaço e do tempo na sala de aula, possibilitando a comunicação presencial e virtual, o estar junto, num mesmo espaço ou em espaços diferentes (conhecido como educação à distância). Já Kenski (2001) entende a tecnologia como algo a ser utilizado para a transformação do ambiente tradicional da sala de aula (local, normalmente, desinteressante e com pouca interação entre alunos e professor), buscando através dela criar um espaço em que a produção do conhecimento aconteça de forma criativa, interessante e participativa, de modo que seja possível educador e educando aprenderem e ensinarem usando imagens (estática e ou em movimento), sons, formas textuais, e com isso adquirirem os conhecimentos necessários para a sobrevivência no dia-a-dia em sociedade.

Essa forma de pensar as Tecnologias de Informação e Comunicação (TICs), enquanto instrumentos formadores de sujeitos no espaço escolar, constrói-se não apenas com a presença (ou inserção) das ferramentas tecnológicas na escola. Ela depende, antes de tudo, de uma formação do professor, que o torne capacitado à mediar TICs, alunos, conhecimentos e realidade. Para Porto (2003b), essa questão vai além da simples instrumentalização tecnológica do educador ou da escola, pois a autora afirma que o uso das TICs como recurso de apoio ou ferramenta de auxílio, evidência um ensino preocupado com a ilustração de suas proposições e não com o processo intermediado pelas tecnologias.

Assim, o uso das TCIs na educação depende antes mesmo da sua existência na escola, da formação do professor para lidar critica e pedagogicamente com elas. É necessário que o professor conheça as tecnologias os “... suportes mediáticos e todas as possibilidades educacionais e interativas das redes e espaços virtuais para [melhor] aproveitá-las nas variadas situações de aprendizagem e nas mais diferentes realidades educacionais." (Kenski, 2001, p. 75). Um docente que saiba trabalhar com as informações novas e/ou velhas, coletando-as através das diversas TCIs disponíveis, de tal modo que consiga, juntamente com o seu aluno, um movimento de coleta e transformação de informações em conhecimento, auxiliando-os na aprendizagem.

É partindo dessa perspectiva, que a presente pesquisa investigou como alunos e professores dos cursos de Licenciatura da UFPel lidam com a tecnologia informática e/ou digital (computador - interfaces - e Internet) no contexto dos Laboratórios de Informática da Graduação (LIGs). Os LIGs são espaços disponibilizados a alunos e professores para acesso aos computadores e à Internet. Nesta pesquisa, utilizou-se os LIGs sediados nos Institutos de Ciências Humanas, Ciências Biológicas e Física e Matemática, pelo fluxo constante de atendimento à população universitária e especialmente, por proporcionarem aos docentes e discentes dos cursos de Licenciatura, o acesso às tecnologias digitais.

Tendo sido selecionado os sujeitos da pesquisa e o campo, procurou-se iniciar a coleta de dados. Para tanto, foram usados três instrumentos para o recolhimento de informações sobre o contexto dos LIGs, que possibilitassem a identificação da real função desses espaços permitindo ver como os docentes e os discentes dos cursos de Licenciatura visualizam a informática na universidade em geral e no curso de formação em particular. Desse modo, nessa pesquisa utilizou-se das seguintes ferramentas: observação de campo, na qual o pesquisador tem vivenciado o dia-a-dia de alunos e professores no espaço dos LIGs; questionário virtual, disponibilizado na página da UFPel de modo a coletar dados sobre a relação de professores e alunos com as TCIs na realidade diária; e entrevista semi-estruturada com dez professores e quinze alunos (de 
diferentes cursos de Licenciatura) selecionados a partir dos seguintes critérios: disponibilidade para a pesquisa, uso dos laboratórios, semestre de atuação e interesse pela temática.

Como a investigação em foco encontra-se em andamento, o trabalho aqui apresentado tem o objetivo de trazer dados que refletem sobre dois pontos que parecem ser de fundamental importância quando se discute a inserção das tecnologias digitais no contexto de formação do professor: a estruturação tecnológica de UFPel e a visão de professores e alunos sobre a inserção das tecnologias de informática no contexto educacional da UFPel.

\section{Laboratórios de Informática da Graduação da UFPel: reflexo do "abandono" da universidade pública}

O momento vivido no Brasil pela universidade pública, mais especificamente pelas universidades federais, segundo Catani e Oliveira (2001) é reflexo da reestruturação das políticas públicas do Estado, que evidencia o atendimento às exigências dos organismos internacionais, entre eles do Banco Mundial, que traz como princípio norteador dessas reformas do Estado, o abandono gradual da aplicação de recursos públicos para o financiamento do ensino superior. Na óptica dos autores, “... esse empreendimento se coaduna, no Brasil, com uma progressiva limitação de recursos financeiros da minimização do Estado e, conseqüentemente, (sic) [a] redução dota fundos públicos para as políticas públicas.” (2001, p. 180).

Para Chauí (2001), a Reforma do Estado brasileiro tem por finalidade modernizar e racionalizar os serviços estatais. Trata-se de repensá-los e distribuí-los em setores, sendo um desses designado "Setor de Serviços Não-Exclusivos do Estado", o qual pode ser desenvolvido por instituições não estatais, na qualidade de prestadoras de serviços. Nessa perspectiva, caberia ao Estado prover esses serviços, sem ter a obrigação de executá-los diretamente ou de elaborar regras (ou políticas) públicas para quem os presta. A autora aponta que entre os serviços não-exclusivos do Estado podem estar incluídos "a educação, a saúde, a cultura e as utilidades públicas", sendo que esses deixariam de ser direitos sociais para se tornar serviços definidos pelo mercado. Portanto, a Reforma encolhe o espaço público democrático dos direitos e amplia o espaço privado não só ali onde isso seria previsível - nas atividades ligadas a produção econômica -, mas também onde não é admissível - no campo dos direitos sociais conquistados". (Chauí, 2001, p. 211).

A Reforma do Estado, aqui analisada de forma resumida, é resultado do chamado "colapso da modernidade" (Chauí, 2001, p. 211), onde acontece o declínio do modelo de Estado de Bem-Estar Social, em que o Estado procura controlar as atividades econômicas, agrícolas, científicas, tecnológicas e industriais básicas através do subsídio, garantindo condições sociais elementares aos seus cidadãos (saúde, educação, etc.). Em contrapartida, a "nova" perspectiva de Estado (neoliberal) aponta na direção da organização eficiente e mínima, que tende a se responsabilizar pelo controle da economia e transforma serviços essenciais, como educação e saúde, em serviços nãoexclusivos do Estado (Silva Jr., Carvalho, 2003; Chauí, 2001; Catani, Oliveira, 2001).

Para Silva Jr. e Carvalho (2003) esse modelo de Estado aponta na direção do afastamento gradual da responsabilidade do poder público com o ensino superior. No entender dos autores há a consolidação do que se denominaria espaço social do aparentemente "semi-público" e do "semi-privado" (p. 30-31). Nessa óptica, as Instituições Federais de Ensino Superior (IFES) deixam de ser responsabilidade unicamente do Governo Federal e tornam-se fundações publicas de direito privado. Essa 
questão é reforçada por Amaral (2001), que aponta uma profunda crise no financiamento da IFES, já que segundo o autor, o Estado tem, basicamente, mantido o salário de professores e funcionários (ativos e inativos) e deixado a manutenção das ferramentas que dão suporte ao ensino, pesquisa e extensão em segundo plano. Ristoff (2001) define a crise financeira vivida atualmente pela IFES, como sendo um "matar silencioso", forma de afastamento gradual do Estado das suas responsabilidades básicas com o ensino superior, deixando aos poucos de manter, financeiramente, a estrutura universitária. Na UFPel, essas "novas concepções" de políticas públicas de financiamento do ensino superior podem ser observadas na desestruturação das bibliotecas setoriais, na falta de recursos para a manutenção dos serviços de apoio estudantil (casa do estudante, restaurante universitário, auxílio transporte, etc.) e, olhando mais especificamente para o campo dessa pesquisa, é possível ver a deterioração dos LIGs, ou seja, o sucateamento dos computadores, do espaço físico, da rede de Internet (entre outras).

Na tabela 1, pode-se visualizar como os três LIGs selecionados como campo de pesquisa na UFPel, são exemplos claros desse "matar silencioso" do ensino superior. A seguir apresenta-se dados referentes ao número de alunos matriculados em cursos de Licenciatura nos Institutos pesquisados, que refletem a responsabilidade de atendimento de cada um desses ambientes. Por exemplo: o Laboratório do Instituto de Ciências Biológicas (ICB) atende ao curso de Ciências Biológicas num total de 186 alunos; o LIG do Instituto de Física e Matemática (IFM) disponível ao curso de Física e Matemática com 255 alunos; e o laboratório do Instituto de Ciências Humanas (ICH) que concentra os cursos de História, Geografia, Filosofia, Pedagogia e Ciências Sociais num total de 937 alunos. Observa-se que, as normas dispostas no Programa de Gestão dos Laboratórios de Informática da Graduação (2003), tornam-se flexíveis, uma vez que, atualmente, esses espaços atendem a estudante de quase todos os cursos da UFPel, por estarem dispostos em locais estratégicos, onde o fluxo de aluno é constante e pela pouca disponibilidade de acesso a computadores e Internet. Salienta-se que os professores não fazem parte desses dados, pois a maioria tem computador em sua sala de trabalho ou em espaços disponibilizados pelas faculdades (salas de estudo). Seguindo essa lógica, são três LIGs, com um total de 24 computadores (acima de Pentium I ou equivalente - dados da Pró-Reitoria de Graduação) que atendem cerca de 1378 alunos (conforme matriculados em 2003), ou seja, vê-se uma média de 57 estudantes por máquina. Avaliando-se apenas os computadores conectados à Rede de Internet, os LIGs disponibilizam 18 máquinas, que equivale a atender, aproximadamente, 76 alunos por máquina.

\begin{tabular}{|c|c|c|c|c|c|}
\hline \multicolumn{6}{|c|}{$\begin{array}{ll}\text { TABELA } 1- & \text { NÚMERO DE ALUNOS MATRICULADOS NOS CURSOS DE } \\
& \text { LICENCIATURA DOS INSTITUTOS DE BIOLOGIA, FÍSICA E } \\
& \text { MATEMÁTICA E CIÊNCIAS HUMANAS EM COMPARAÇÃO } \\
& \text { COM A QUANTIDADE DE COMPUTADORES (CONECTADOS } \\
& \text { OU NÃO A INTERNET) DISPONIBILIZADOS NOS LIGs DESSES } \\
& \text { INSTITUTOS - } 2003\end{array}$} \\
\hline LIGs & $\begin{array}{c}\text { Alunos } \\
\text { Matriculados }\end{array}$ & $\begin{array}{c}\text { Computadore } \\
\text { s por LIG }\end{array}$ & $\begin{array}{c}\text { Média } \\
\text { (al/comp) }\end{array}$ & $\begin{array}{c}\text { Computador } \\
\text { es Internet }\end{array}$ & $\begin{array}{l}\text { Média } \\
\text { (al/Int.) }\end{array}$ \\
\hline$\overline{\mathrm{ICB}}$ & 186 & 11 & 17 & 5 & 37 \\
\hline IFM & 255 & 5 & 51 & 5 & 51 \\
\hline $\mathrm{ICH}$ & 937 & 8 & 117 & 8 & 117 \\
\hline TOTAL & 1378 & 24 & 57 & 18 & 76 \\
\hline
\end{tabular}


FONTE: Dados de alunos matriculados foram coletados junto ao material produzido pela universidade (UFPel em números 2003). Quanto ao número de computadores as informações foram coletadas nos próprios LIGs.

NOTA: As médias apresentadas na tabela foram todas, quando necessário, arredondadas para baixo.

Esses dados demonstram a desestruturação da universidade , cujos problemas atingem, principalmente, a formação do futuro professor. Os professores e alunos entrevistados retrataram as dificuldades das Licenciaturas para ter acesso, por exemplo, às referências bibliográficas de qualidade nas bibliotecas da UFPel, e ao buscarem os LIGs para pesquisar novas informações (ação considerada de rotina), são obrigados a enfrentarem filas; além de não ter o acesso impresso desses documentos, já que boa parte dos laboratórios não possui impressora e quando possui, a impressora é matricial o que leva mais tempo para imprimir. As palavras da professora do curso de Ciências Biológicas refletem essa situação: “... como vamos trabalhar genética com livros que já estão na biblioteca há quase dez anos? Se não fosse a Internet, não teríamos como trabalhar esse conteúdo." A fala da professora expõem a situação no dia-a-dia dos diversos cursos e vem reforçar o atual desmonte da universidade pública federal.

Tecnologias de informática no contexto educacional: uma análise a partir da óptica de professores e alunos universitários

De acordo com Porto (2003a, 2003b, 1998), Kenski (2003, 2001) Orozco (2002) e Moran (2000), as TICs devem fazer parte do contexto educacional. Os autores ressaltam que o uso dessas ferramentas tem que ser de forma consciente e com conhecimento (ou domínio) das possibilidades e dos modos de usá-las. A incorporação das TICs na escola, simplesmente agregadas ao já estabelecido, transformando-a em um local "modernizado", sem proporcionar discussões sobre os conteúdos, processo de ensino e aprendizagem e paralelamente sobre a forma de os sujeitos escolares (professor, aluno, direção, coordenação pedagógica) se relacionarem, acaba gerando esforços inúteis, visto que apenas levar as TICs para o contexto escolar não gera novas maneiras de ensinar. No entender de Porto (2003a) e Orozco (2002) o "tecnicismo" por si só" não pressupõe mudanças ou melhorias para a educação, ou seja, não garante avanços na aprendizagem do aluno. Essa transformação no processo educativo depende sobretudo da superação do modelo tradicional de educação, que impede a interação e mediação dos sujeitos escolares com as TICs e com os conhecimentos advindos delas. Segundo Orozco (2002 p. 65), a introdução de TICs no contexto escolar mexicano, está demonstrando, através de pesquisas, que a "aprendizagem não se modifica, ou se modifica minimamente, e que inclusive em alguns casos é até menor à que usualmente se realiza sem as novas tecnologias".

Tendo essa idéia como ponto de partida, tem-se indagado a professores e alunos, sobre a importância da inserção das tecnologias de informática no meio escolar (entendo esse meio escola, ensino fundamental, médio e superior). A partir dessa questão, a resposta que mais tem aparecido, cerca de $90 \%$ (noventa por cento), procura afirma que "isso é importantíssimo", ou seja, boa parte dos entrevistados, afirmam que na atual realidade social é impossível pensar a formação adequada de um cidadão sem que esse tenha acesso ao computador e às ferramentas desse meio que oferecem informações e maneiras de produzir o conhecimento.

Em contrapartida, 70\% (setenta por cento) dos professores universitários, ligados aos cursos de Licenciatura na área de ciências exatas e ciências humanas e ciências biológicas, questionados sobre o trabalho com as tecnologias, apontam que, normalmente, não costumam usá-las e quando o fazem é para projetar conteúdos através 
do data-show ou demonstrar (ou testar) alguma experiência, por exemplo em Física, Química ou Biológica. Para os professores, essa atividade reforça, os conteúdos vistos em sala de aula. Eles deixam transparecer em suas falas, as contradições do seu modelo de atuação, já que dizem não conseguir visualizar a formação de um cidadão sem o contato com as tecnologias digitais e suas possibilidades, mas oferecem uma formação a seus alunos (também futuros professores) sem que ao menos discutam o avanço e utilidade das tecnologias na realidade social e educacional. Dois professores da área de ciências humanas, ao serem questionados sobre essa contradição, apontam que não usam tecnologia, devido a "...grande dificuldade em reservar o LIG..." e, principalmente, “... por ser esse um espaço muito precário, com computadores lentos e de difícil instalação de Software” (professores da área de Ciências Humanas).

Os professores que proporcionam esse contato, afirmam que a dificuldade está basicamente na forma como funcionam os laboratórios, uma das professoras conta que : “... instalamos um programa e trabalhamos a primeira aula e no outro dia quando fomos para a segunda aula os dados, ou até mesmo, o programa já havia sido desinstalado e por isso não conseguíamos fazer o trabalho andar”. (Professora do Curso de Química - Licenciatura e Bacharelado). Essa professora também afirma que torna-se difícil trabalhar com os alunos, pois “... muitos não sabem nem ligar o computador... eles têm medo de apertar o botão e tenho que, antes de tudo, ensiná-los a fazer isso".

Já para $70 \%$ (setenta por cento) dos alunos tornou-se impossível pensar a formação, intra e extra escolar, sem o uso do computador e de suas ferramentas. Eles apontam que não conseguem se desvincular dessa tecnologia; “... eu não vivo sem Internet... uso para fazer pesquisa, entregar trabalhos e manter contato com professores e colegas...”. (Aluno do curso de Letras - Habilitação em Espanhol). Outros estudantes ainda não sentem tanta necessidade do computador e da Internet. Eles vêem essas tecnologias como uma nova possibilidade de pesquisa, de estudo e comunicação (e-mail) sem ser algo vital para o dia-a-dia na educação.

\section{Considerações finais}

No contexto da Universidade Federal de Pelotas em geral, e no contexto dos cursos de Licenciatura em específico, a análise da inserção das tecnologias de informática, tem possibilitado visualizar a complexa contradição existente entre concepções teórica, práticas de atuação, documentos e normas oficiais e o dia-a-dia de formação em sala de aula e nos LIGs. Por exemplo: em dois LIGs pesquisados (ICH e ICB) segundo o quadro de controle dos equipamentos da Pró-Reitoria de Graduação, existem 28 computadores, quando na realidade eles dispõem para o uso dos alunos de 20 computadores. Estes dados refletem a complexa contradição existente entre teoria e prática no contexto universitário. Embora os professores e alunos entendam a tecnologia como importante para a sociedade e formação docente, nas práticas nos laboratórios não se observa a aplicação destes postulados. Nas palavras de um dos professores entrevistados “... a UFPel tem uma fachada, nós estamos num prédio que as portas se abrem [referindo-se à unidade das Ciências Humanas] ... a UFPel tem uma cara, consegue isso... consegue laboratórios... [mas não tem professores para dar aula] $e$ temos que tapar buracos... mas ai, isso não aparece... Então eu acho que os laboratórios também são um problema e eu acho que isso é uma coisa a ser dita... tem uma coisa que é de fachada mas não tem de fato. Falando metaforicamente, tem aquilo que tu olha, mas tu não conhece a interioridade da coisa". (professor da área de Ciências Humanas). 


\section{Referências Bibliográficas}

AMARAL, C. N. Crise no financiamento das instituições federais de ensino superior. In: TRINDADE, H. (Org.). Universidade em ruínas: na república dos professores. $3^{\mathrm{a}}$ edição, Petrópolis, RJ: Vozes/ Porto Alegre, RS: CIPEDES, 2001. p. 191-200.

CATANI, A. M.; OLIVEIRA, J. F. A universidade pública no Brasil: identidade e projeto institucional em questão. In: TRINDADE, H. (Org.). Universidade em ruínas: na república dos professores. $3^{\mathrm{a}}$ edição, Petrópolis, RJ: Vozes/ Porto Alegre, RS: CIPEDES, 2001. p. 179-190.

CHAUÍ, M. A universidade em ruínas. In: TRINDADE, H. (Org.) Universidade em ruínas: na república dos professores. $3^{\mathrm{a}}$ edição, Petrópolis, RJ: Vozes/ Porto Alegre, RS: CIPEDES, 2001. p. 211-222.

D’AMBRÓSIO, U. Novos paradigmas de atuação e formação de docente. In: PORTO, T. M. E (Org.). Redes em construção: meios de comunicação e práticas educativas. Araraquara, SP: JM, 2003. p. 55-77.

KENSKI, V. M. Em direção a uma ação docente mediada pelas tecnologias digitais. In: BARRETO, R. G. (Org). Tecnologias educacionais e educação a distância: avaliando políticas e práticas. Rio de Janeiro: Quartet, 2001. p. 74-84.

Tecnologias e ensino presencial e a distância. Campinas, SP: Papirus, 2003.

LÉVY, P. As tecnologias da inteligência: o futuro do pensamento na era da informática. Tradução: Carlos Irineu da Costa. 9ª edição, Rio de Janeiro: Ed. 34, 2000.

MORAN, J. M.; MASETTO, M. T.; BEHRENS, M. A. Novas tecnologias e mediação pedagógica. Campinas, SP: Papirus, 2000.

OROZCO, G. G. Comunicação, educação e novas tecnologias: tríade do seculo XXI. In: Revista Comunicação \& educação, São Paulo, n. 23, p. 57-70, jan./abr. 2002.

PENTEADO, H. D. Comunicação escolar: uma metodologia de ensino. São Paulo: Ed. Salesiana, 2002.

PORTO, T. M. E. Educação para a mídia/pedagogia da comunicação: caminhos e desafios. In: PENTEADO, H. D.(Org.). Pedagogia da comunicação: teorias e práticas. São Paulo: Cortez, 1998. p. 23-50.

As tecnologias e a formação docente na escola. FaE/UFPel, 2003a.

As mídias e os processos comunicacionais na formação docente na escola. In:

PORTO, T. M. E (Org.). Redes em construção: meios de comunicação e práticas educativas. Araraquara, SP: JM, 2003b. p. 79-110. 
RISTOFF, D. A tríplice crise da universidade brasileira. In: TRINDADE, H. (Org.) Universidade em ruínas: na república dos professores. $3^{\mathrm{a}}$ edição, Petrópolis, RJ: Vozes/ Porto Alegre, RS: CIPEDES, 2001. p. 201-210.

SILVA Jr. J. dos R.; CARVALHO, C. P. de F. Novas faces da educação superior no Brasil: neopragmatismo institucionalizado. In: Eccos Revista Científica, São Paulo, v. 5, n. 1, p. 11-38, jun. 2003.

UNIVERDIDADE FEDERAL DE PELOTAS. Normas do programa de gestão dos laboratórios de informática da graduação. Disponível em <http://prg.ufpel.edu.br/Regulamento_LIGs.doc> Acesso em: 22 nov. 2003.

Ufpel em números 2003. Pelotas, RS: 2004.

Quadro de distribuição de computadores nas unidades da Universidade

Federal de Pelotas. (documento impresso) 